\title{
A Tribute to Robert W. Entenmann (Bob)-12/10/16
}

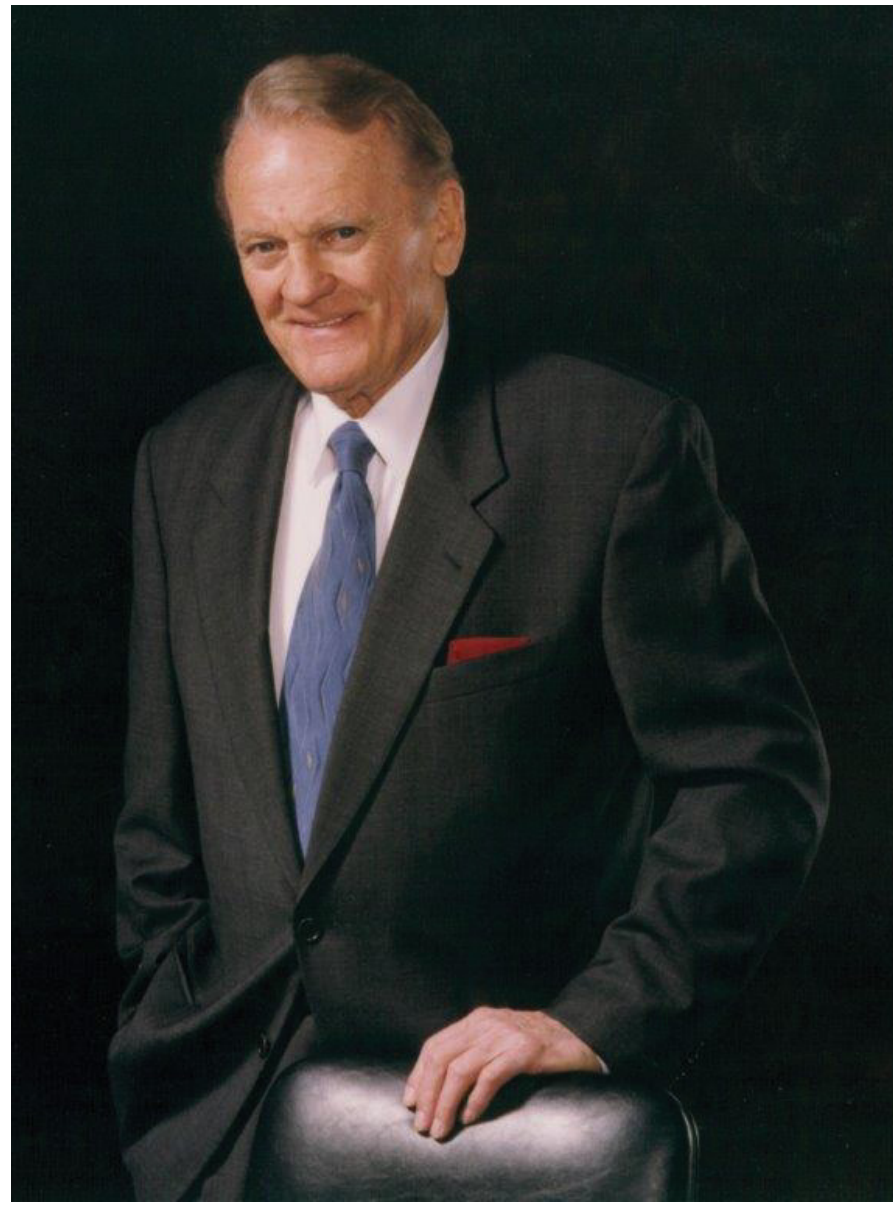

Mr. Robert W. Entenmann (Bob)

It is with profound sorrow that Barbara Goldstein and I share with colleagues, friends and tinnitus patients worldwide the passing of our mutual friend and benefactor Robert Entenmann. We share with you a sense of loss of a friend and celebrate the man. We have been blessed to have known Robert W. Entenmann (Bob), not only as a benefactor-but as a special friend.

Robert W. Entenmann, age 88, passed on 9/15/16. His beloved daughter Jacquelyn reported that he had returned home from a fishing trip to the Bahamas. He suffered a fall at home in Lauderdale by the Sea in Florida from which he did not recover. His passion was boating and fishing. He was part of the Entenmann family who came from Germany to the USA, whose grandfather started a baked goods company in Brooklyn, and which as a family, father, mother, and he together with his brother, achieved the American Dream. The baked goods were well appreciated locally for their excellence of quality and taste. Over the years the family prospered, but never forgot its start, and always gave back to family, friends and community. Mr. Entenmann demonstrated to all the moral example of dedication to family, and charitable contributions to science and community. He retired from the family business after it was sold in 1978 . He purchased a Sound Avenue potato farm soon after and turned it into a farm to raise thoroughbred race horses, known as "Big E Farm." In 1995, he planted 18 acres of vitisvinifera, the first steps in creating Martha Clara Vineyards, which he named for his mother. In all his ventures his successes reflected what coworkers and managers said: "He was always about sharing something, "a real pleasure to work for". The establishment of the Long Island First Investors, by Mr. Entenmann, together with Robert Rosenthal and his team reflects the vison of a leader and team builder interested not only in oneself but community.

We met Mr. Entenmann as a patient initially in $11 / 03 / 1978$. What started as a doctor/patient relationship developed over the years into one of friendship, and trust in each other. He was the perfect benefactor. He listened, advised, and questioned-but never-directed or interfered in the research efforts. We respected his privacy, intellect and interest in the advances taking place in the ear in auditory science and neurosciences for brain, which were and continue to be translated as appropriate for tinnitus. When we spoke together of an evolving understanding of tinnitus, its underlying biology, and advances in the auditory and neurosciences-he was a good listener as evidenced in his questions and discussions that followed. We listened to each other. Our friendship and respect for each other increased over the years. The initiation of the concept of A Research Center for Tinnitus dedicated to advances for tinnitus theory, diagnosis and treatment reflected an increasing frustration on the part of Mr. Entenmann of the lack of appreciation by professionals on the significance of the tinnitus symptom on the quality of life of the tinnitus patient, no specific identification of the underlying biology, development of a pharmacology treatment for tinnitus, or significant advances for tinnitus diagnosis and treatment. The result was the naming of and establishment in 1994, by Mr. Entenmann, Barbara and myself, of the Martha Entenmann Tinnitus Research Center, Inc. (METRC). Scientifically, whatever Barbara and I have achieved in the scientific community for tinnitus is due to the support of the METRC and Robert W. Entenmann. Included are publications for tinnitus, in excess of 200 publications, reflecting investigations in basic science, neuroscience, and clinical medicine for tinnitus diagnosis and treatment, and drug development. Annual METRC reports were shared with Mr. Entenmann. Contributions were made for investigative collaborative protocols for tinnitus diagnosis and treatment, drug development, otolaryngology education targeting the American Academy of Otolaryngology Head and Neck Surgery (AAO-HNS), and establishment of the International Tinnitus Journal (ITJ), the first medical journal dedicated to the symptom of tinnitus.

Bob brought us together as friends. Together as friends we share a loss that in itself cannot be replaced- 
but-by example as demonstrated by our mutual friend, Bob Entenmann, will help us to continue and not forget. We have in the past and will in the future remember his friendship, generosity, contributions to the community, and support for the evolving science of tinnitus dedicated to the tinnitus patient, as we continue to benefit from his generosity.

Robert W Entenmann was a visionary, a benefactor, a mentor, an individual who made a difference by seeking something better that what existed in the present.
His philanthropy and vision for tinnitus investigation, diagnosis and treatment contributed to advances in what has been identified since 1991 as a new multidiscipline, Tinnitology. He is a model for future benefactors to follow.

To Jacqueline, and the Entenmann family, a special thank you for sharing with us the attention of your Dad. We celebrate together with you and your family his humanity, friendship, generosity, and sense of responsibility to family, community and science.

Thank you Bob,

Barbara B Goldstein, PhD (Barbara) Abraham Shulman, M. D. F.A.C.S. (Abe) 